\title{
Sustainability of social being as an effect of transforming non-random events into constructive energy (synergetic and transcendent approaches)
}

\author{
Julia Kharchenko ${ }^{1, *}$, Sergej Kharchenko ${ }^{1}$, Olena Sidorkina ${ }^{1}$, Alla $_{\text {Fabrika }}{ }^{1}$, and Oleg Rusul ${ }^{1}$ \\ ${ }^{1}$ National Aviation University, 1, Kosmonavta Komarova ave, 03058, Kyiv, Ukraine
}

\begin{abstract}
The analysis of the conversion of non-random events into constructive energy has been conducted. "Non-randomness" is shown as a complex philosophic and theological category that has a deep eschatological meaning, actualizing the highest meaning of divine being, and a lot of manifestations of being in all its dialectical complexity and antinomy of its logic. On this basis, the main purpose of the research was conceptualization of the sustainability of social being as an effect of transforming non-random events into constructive energy. Synergetic and transcendent approaches as the theoretical basis of this research showed that the process of converting randomness into non-randomness is quite laborious, it requires a long time and as a result of this transformation, a pattern is revealed that allows synchronizing the synergy of scientific ideas, theories of being, scientific pictures of the world, as well as approaches to building a new everyday life in social virtuum. The results of the research confirmed that non-random events can be someone or something manageable and consciously ordered which creates sustainability. Sustainability is shown as the ability of society as a complex system to maintain its current state under the influence of external and internal factors. Random events are transformed into non-random events, since this is logical for the human mind and necessary for a comfortable life in society. If the social system becomes emergent, then applicable to historical time and the situation, appropriate approaches, evaluation criteria, methods, strategies and tactics are developed to minimize fluctuations.
\end{abstract}

\section{Introduction}

It can be noted that humanity at all times strove for a sustainable life, a predictable future. Psychologically, a person does not accept fatal accidents and therefore begins to study their essence. Random events today are perceived as a multitude of variables that sets the line between our knowledge and ignorance. Mind and reason are trying to overcome this boundary. The main task of modern science is to manage not only social, physical,

\footnotetext{
* Corresponding author: kharchenkojv@gmail.com
} 
biological, chemical, quantum, cosmic processes, but also events by converting random events into nonrandom ones.

The event as such is a category of philosophy designating a cardinal reconstruction of traditional metaphysics into a new metaphysics at the turn of the 20th and 21 st centuries. The term "event" represents the most important issues of modern science, relevant not only the origin of human, society, the universe, space-time, the perspectives of the digital world, but also the search for the meaning of life in all conceivable and inconceivable worlds. I. Devterov and I. Skyba rightly emphasize that space and time as the concepts that embody the physical model of the world, demonstrate at present a number of surprises. The conceptual power of philosophy and physics, which had been fully formed by the beginning of the previous century, at the beginning of the 21 st century turned out to be in the state that can be characterized as "unstable", since, along with old methodologies fundamentally new ones are being created due to a number of objective circumstances. Time, conventionally recognized by physicists as the fourth dimension, "behaves" nevertheless differently, that is not as the "dimension" itself, however maintaining at the same time its conditional linearity, but not its homogeneity. Once within the coordinate system of 3-dimensional space, which would either become denser or would stretch, we would lose the feeling of objective reality, i.e. the reality of the objective world. However, this is exactly what happens when we are in the digital world. This is an objective process, whose analogues have not been known by the history yet. The space-time continuum, which we perceive to a certain degree, conflicts however with the ontology of the digital world, not excluding in this case our ideas about the matter and consciousness [1]. It can be argued that, not seeing the general picture of the world, the beginning and the goal, the human mind perceives natural phenomena as random events.

Thus, a random event became the subject of research in mathematical science. Multiple repetition of such an event by experiment portends the identification of patterns, as well as the construction of fundamental laws of nature. A non-random event falls into the field of view of philosophy and theology as a complex category that reflects the essence of transcendental nature. Moreover, if for theology "non-randomness" is a category that has a deep eschatological meaning, actualizing the highest meaning of divine being, then for philosophy it is a lot of manifestations of being in all its dialectical complexity and antinomy of its logic.

From time to time, the goals of fundamental science and philosophy diverge in view of the fact that the science considers phenomena from a purely technical, functional, rather than spiritual, value, existential point of view, which leads to a crisis of science, society, and personality. The philosophical and theological position regarding the "what controls things" extrapolates the control phenomenon to the level of universality. The modern theory of management also focuses more on the technical capabilities of the human brain, but practically does not consider the sphere of spirit as the basis of personality, the driving force of creativity in its various manifestations, or it considers, but not to a sufficient extent. It is the personality that produces the creative energy necessary for the constructive development of the holistic architectonics of society.

In technical science, electricity and energy produced in various volumes replace the spirit and soul. The concept of "energy" is also perceived as a material resource, which is more likely to have economic, political, and production significance. But the value of energy is highly significant in the transcendental sense of the word. It is important not to confuse it with mining, namely mining or material rewards, or increasing the computing power associated with the activity of creating new structures (or new blocks in the block chain) to provide new business functionality.

The maximum use of scientific and intellectual resources, taking into account new technologies in the planning of professional activities with minimal energy consumption, of 
course significantly changes the level of people's daily lives. However, the excessive physicality load of the "energy" category excludes its understanding in the measurement of transcendence. Such attributes of energy as "higher power", "creative activity" and "driving force" are associated with the panlogical structure of nature and society. Therefore, they are the mechanisms that generate stability under the condition of the sequential determination of events and processes by a rational, irrational, spiritual, creative, searching person. This actualizes the use of synergetic and transcendental approaches in identifying and studying the "effect" of the conversion of nonrandom events into constructive energy in social being.

\section{Materials and Methods}

Energy can conditionally be called a "constructing" tool, since it is continuously being transformed, being preserved in various physical states. For comparison, in thermodynamics, the conservation law is formulated in the form of the first principle of thermodynamics, which shows that a change in the internal energy of a thermodynamic system upon its transition from one state to another is equal to the sum of the work of external forces on the system and the amount of heat transferred to the system, and does not depend on the method, by which this transition is carried out.

In social being, transformation depends on the productive work and creativity of millions of people. The synergy of events in society, as in any other complex system, demonstrates the increasing effect of the interaction of two or more factors (people and their actions), characterized in that the combined action of these factors significantly exceeds the simple sum of the actions of each of these factors.

In our previous research, we have shown that society as the innovative space has a complex structure and configuration, but its space-time frame is uncertain due to the high dynamics. At the same time, it is presented as a kind of virtuum - multidimensional and multi-level formation, forming a new image of society and, at the same time, generating and combining new knowledge. In today's society a so-called "new effect" acts because there is a search for qualitatively new ideas and solutions, and there is a conflict between old and new ideologies, generations, and images of thought. Knowledge and innovation become the fundamental dominants of life in the model of society that is being formed at the moment. This model combines the characteristics of a new type of society informational, cybercultural, technogenic, virtual, and innovative. On this basis, we correlate innovative creations and new epistemes, which are the foundation of the innovative space [2]. Such a model of society as a virtuum shows its emergence. In order to overcome emergence, projecting the appearance of properties in the social system that are not inherent in each of its elements, as well as demonstrating the irreducibility of the properties of the social system to the sum of the properties of its components, it is necessary to exclude by a scientific method the maximum of permissible risks, that is, to manage events and creative people as sources of these events.

We can give examples of special methods that are used today in engineering and production. So, V. Chulkov underlines that the list of works on the specialization of methods and preparation of the study, without highlighting the exact sequence and significance of the work, includes: development of organizational technological management plans for field studies; formation of the composition and structure of the studied parameters; selection of intermediate diagnostic modes for parameter values ("surveys"); technical modification of the equipment hardware; development of specialized software modules for the hardware-software complex; special planning of activities of the studied workers; preparation of research assistants and studied workers for conducting research in specific conditions [3]. If the transformations in each sphere of society are 
productive, then we can talk about the constructive nature of the energy spent by the creative person. Such an approach involves the inclusion of probabilistic and synergetic principles that explain the modeling of a complex system taking into account many uncertain factors.

But there are certain differences. In our opinion, probability theory is used to control random events with their minimum or well-defined number. The synergistic approach shows how vague and unstable the boundary between random and non-random events is.

As already known, a random event is a subset of the many outcomes of a random experiment. With multiple repetition of a random experiment, the frequency of occurrence of an event serves as an estimate of its probability. As a result, some events become impossible, and some reliable. Stochasticity is inherent in random events.

A non-random event is the absence of randomness, validity, justification, regularity, logic. Such events are also inherent in: absurdity or a fact that does not fit into the framework of logical thinking or contradicts logic; fatalism as the unambiguous predetermination of everything that happens (each consequence has a strictly defined reason); determinism or determinability at the general gnoseological level or at the level of a specific algorithm; lack of stochasticity.

Non-random events, therefore, can be someone or something manageable and consciously ordered. This order of things creates sustainability. Sustainability is the ability of society as a complex system to maintain its current state under the influence of external and internal factors. Moreover, the dynamics of the development of human society is stable. If the current state is not saved, then this system is considered unstable.

\section{Results}

Although the theory of stability has formed in the field of technical and physicalmathematical sciences, its role is also actualized in modern philosophical science. The phenomenon of sustainability is considered by social philosophy when studying the patterns of behavior of various political, economic, sociocultural systems under the influence of various external factors. The key goal of applying this theory in the analysis of social processes is to determine the stability reserves of a complex multidimensional, multicomponent, dynamic, diverse, contradictory society. At the same time, society is the result of a set of ideas developed as a result of the embodiment of collective creative energy. This shows the transcendental nature of the role of human in the construction of social reality (see. Fig. 1).

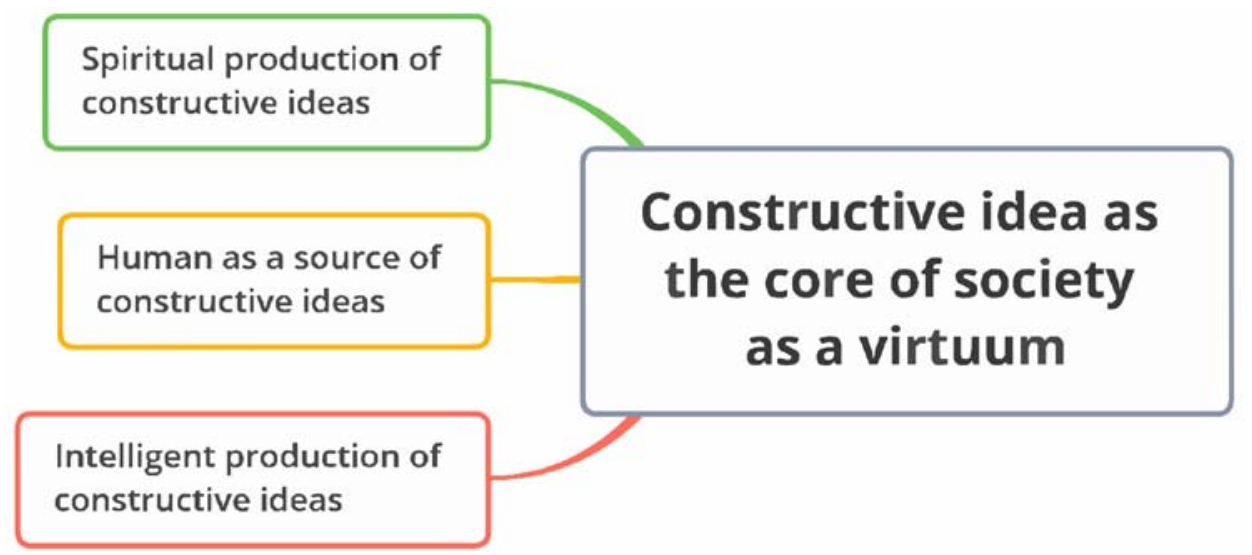

Fig. 1. Constructive idea as the transcendental core. 
In turn, the main task of cybernetics and other mathematical fields of knowledge is to diagnose and predict the stability reserves of processes associated with the operation of large technical systems and resources. Today, various applied problems are being solved related to the adaptation of the theory of stability to modern technical objects. In particular, these tasks are related to the safety issues of the functioning of modern technical means. For example, N. Kazarinov, A. Smirnov, Y. Petrov, A. Gruzdkov confirmed the dynamic fracture of linear oscillator chains and in particular effect related to discreetness of the system. They considered two load cases: abrupt release of a prestressed chain and pulse loading of an undeformed chain. They obtained for the both cases analytical solutions for the chain link deformations and compared these solutions to results for a continuous analogue of chain - elastic rod. They demonstrated that the wave travelling through a chain (resulting either from abrupt release or from deformation pulse applied) is distorted comparing to an elastic rod, which can result into fracture. On the contrary, such effect is not possible for the continuous system. They demonstrated that this effect can be accounted for when structures with explicit discreetness and periodicity are designed and studied, e.g. construction facilities in civil engineering. As another example they took a railway train that could serve of possible application of the studied discrete problem. A railway train moving with a constant velocity can be modeled by a statically uniformly deformed chain of oscillators. Thus, a sudden break of a damaged or worn coupling device can potentially lead to failure of normally functioning coupling devices [4]. Such studies contribute to the development of ultra-complex structures, and in general, the development of engineering in a combination of megaprojects and nanotechnologies. Such projects also change the usual notions of reality and contribute to the modeling of a new way of thinking in the context of technology implementation.

The theory of stability is born in mathematics and is associated with differential equations. A. Lyapunov formulated and proved the main theorems of the theory of stability of motion, and also showed that the solution of the differential equation is stable if the behavior of the solutions, with conditions close to the initial ones, does not differ too much from the behavior of the original solution [5, c. 363].

The Lyapunov function is a scalar function defined on the phase space of the system, with which we can prove the stability of the equilibrium position. The Lyapunov function method is used to study the stability of various differential equations and systems.

The case when the derivative of the function $\mathrm{V}(\mathrm{X})$ in the neighborhood $\mathrm{U}$ of the origin is negative: $\mathrm{dVdt}=(\operatorname{gradV}, \mathrm{dXdt})<0$ means that the angle $\varphi$ between the gradient vector and the velocity vector is greater than $90 \circ$. For a function of two variables, this is shown schematically in Figures 2 and 3.

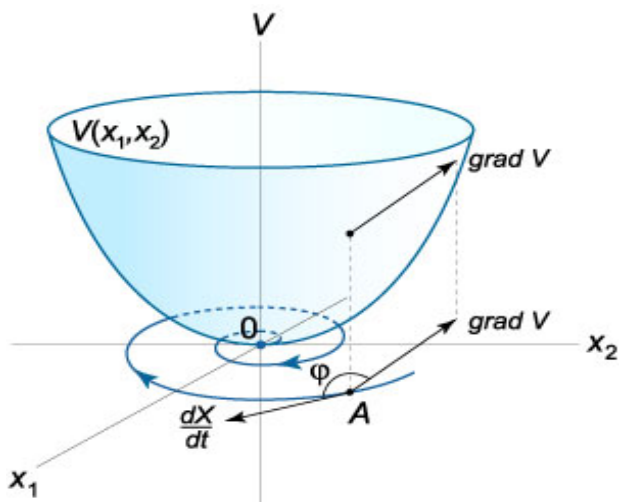

Fig. 2. Position one.

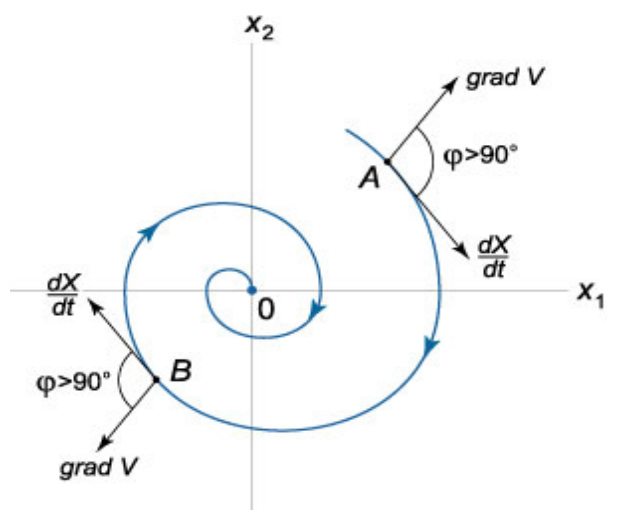

Fig. 3. Position two. 
It is concluded that if the derivative $\mathrm{dVdt}$ along the phase trajectory is everywhere negative, then the trajectory of motion tends to the origin, that is, the system is stable. Otherwise, when the derivative $\mathrm{dVdt}$ is positive, the trajectory tends from the origin, that is, the system is unstable [6].

Lyapunov functions make it possible to establish the stability or instability of a system. The advantage of this method is that here it is not required to know the solution $X(t)$ itself. In addition, this method allows studying the stability of equilibrium positions of non-coarse systems, for example, in the case when the equilibrium point is the center. In the particular case of homogeneous autonomous systems with constant coefficients, the Lyapunov function can be sought in the form of a quadratic form (see Fig. 4, Fig. 5).

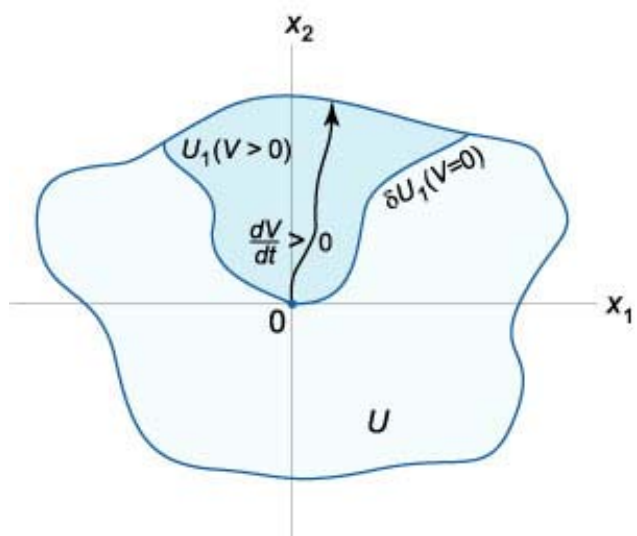

Fig. 4. Position three.

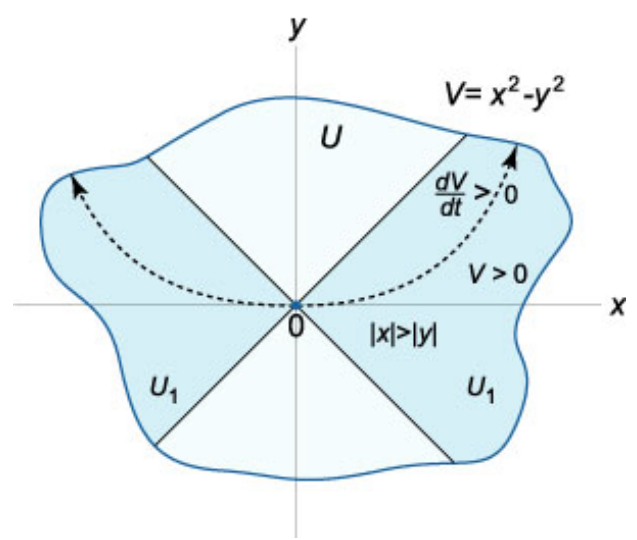

Fig. 5. Position Four.

The disadvantage is that there is no general method for constructing Lyapunov functions [6]. We can conclude that systems simulated and analyzed mathematically are stable if we take into account certain conditions, in which the system develops, and clearly defined parameters of this system. In this case, the stability will be relative, based on the model in which it will be considered.

Modern living conditions increasingly require the use of mathematical models in almost all areas of public life, since society is becoming more complex and oddly "material". The mathematical methods, as well as artificial intelligence, contribute to solving global and narrow applied problems associated with space, medicine, manufacturing, industry, trade, elections and Internet resources. However, a person as a half-transcendental creature does not fit into any mathematical model at all, so it constantly makes adjustments to its life, creating a synergy of new events, and its decisions are not always conscious. But at the same time it orders these events.

Modern society as a virtuum is not only extremely technological, but also fluctuative. L. Honyukova, H. Kleshnya, S. Ordenov, I. Skyba noticed that as a result being in the virtual world of conflicting information flows, a person is released from personal identification markers, such as citizenship, nationality, gender, age, and other factors of selfidentification. At this stage of the society's functioning, the relative independence of the individual's desires (of course, committed to new modified values) from the previous cultural tradition is being achieved. In this regard the question arises: how deep have these changes come into the life of an information age person? [7]. However, each person strives for a stable position in society, wants to control events, calculate risks, without wasting energy.

The fluctuations of society arise due to the huge number of changes that are associated with the behavior of the elements of the system (people), as well as the continuous 
displacement of the vectors of these elements. Small and large groups of people quickly move in the social space, changing its essential configuration and spending huge personal resources in order to gain new stability and vitality. These processes are not accidental, because the global world is rebuilding faster and faster, generating a synergy of events. However, the chaos that has arisen is only conditional; global society in this way strives for a new measure of stability. The most important issue is the effectiveness of managing such a system.

The modern management theory, applying the experience of cybernetics and information theory, demonstrates the ability to search for new principles and methods of managing social processes and strategic objects. In this context, O. Pirogova and V. Plotnikov assumed that the activities of the enterprise should be aimed at ensuring growth in its value, while the indicator of growth in value implies not only an increase in quantitative indicators, but also qualitative growth of the enterprise, i.e. its development, acts as an integral criterion for the quality of management. The concept of VBM is based on the hypothesis that management entities can influence the results of an enterprise's activities, considering the cost of raising capital, as well as comparing the profitability of an enterprise with alternative options for investing capital. The concept of enterprise management is not only based on actions and managerial decisions aimed at increasing current income or planned for the near future, but also is focused on obtaining higher profits (super-profits) in the distant future. This, in turn, can increase the current and future value of the enterprise [8]. Thus, risks are minimized as an element of chance through the development of effective solutions and the production of constructive ideas in the field of enterprise management, in business, and economics, in politics.

To exclude random events from the production process, save energy and resources, minimize risks in developing strategies, selective methods are used. V. Kasyanov, E. Kosenko, V. Kosenko, V. Krymsky underlined that many years of experience in applying the selective method both in science and in engineering practice have proved to be beneficial: saving labor, material and time resources. Typically sets of products and events are applied at various stages of life. This circumstance of finiteness of populations opens up new possibilities for statistical methods in science and engineering practice [9]. That is, the effectiveness of the search for solutions in the formation of a stable system depends on a specific information situation that affects the management of events. The selective methods, used in sifting a significant amount of information, help to organize information, improve its quality and create a constructive informational situation. In this case, we can increase the stability level of the whole system or its individual parts.

I. Rosenberg defines the information situation without the necessary information as "black", and the situation with complete information as "white". In Figure 6, the word "certainty" refers to informational certainty. All real situations between these two extremes are described as "gray" or blurry. Thus, the "gray" analysis system means that we are investigating a situation in which part of the information is known and part of the information is unknown. 


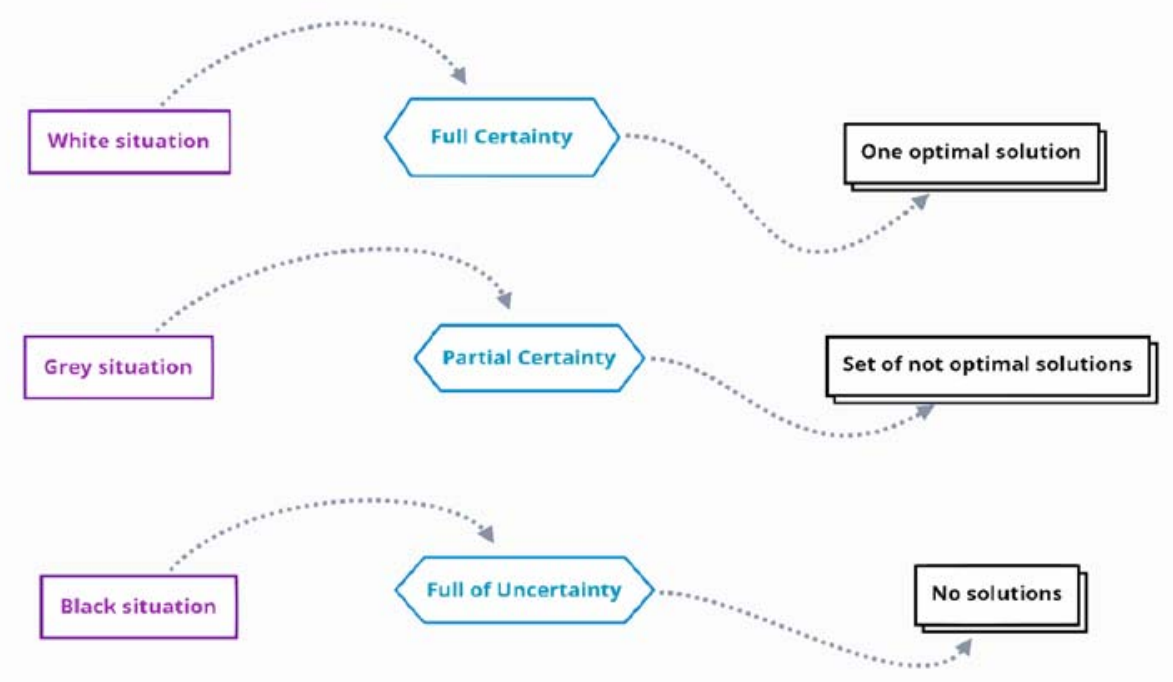

Fig. 6. Randomness and non-randomness as relative phenomena.

With this definition, the quantity and quality of information form a continuum, from a complete lack of information to a complete information certainty. We move from a black situation through a gray situation to a white situation [10]. In this case, we can conclude that a stable social system is formed as a result of the use of significant energy flows. It goes not only about material resources - the amount of time and money spent on work, but also about spiritual factors - morality, hopes, dreams, goals, aspirations, suffering, searches. The stability of society as a complex virtuum depends on the real possibility of realizing the creative incentives of an individual and the colossal efforts of a collective mind and spirit (see Fig. 7).

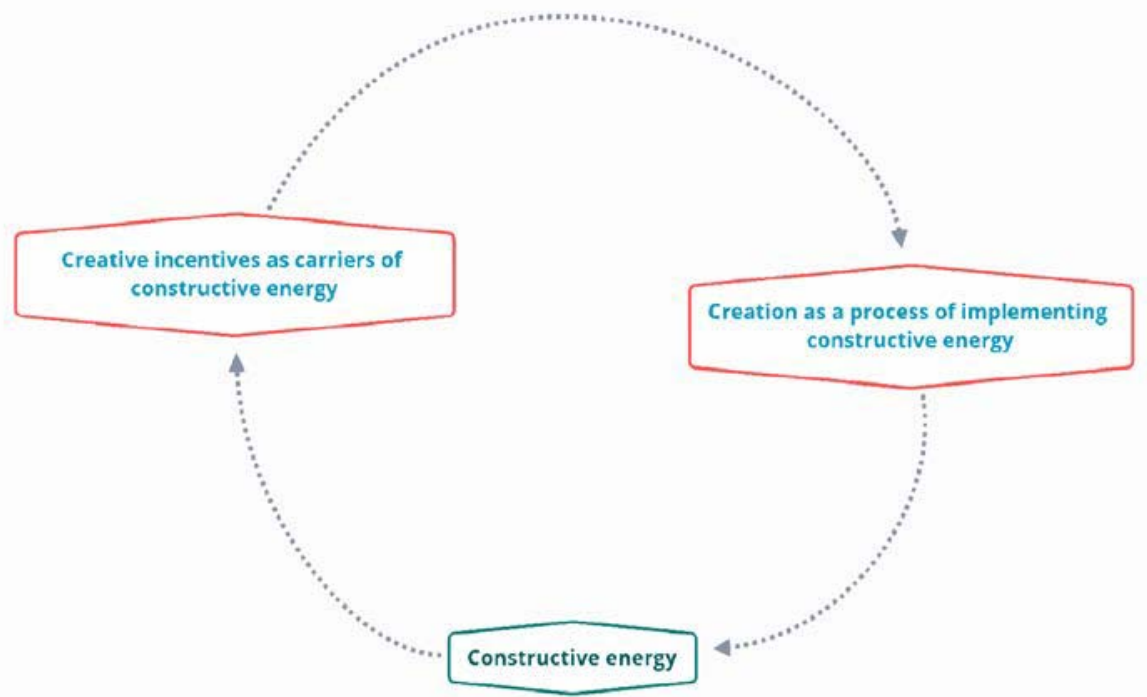

Fig. 7. Social virtuum as the result of implementation of constructive energy. 
One of the key and fundamental in modern philosophy is the question of the source of "constructive energy" (see Fig. 8).

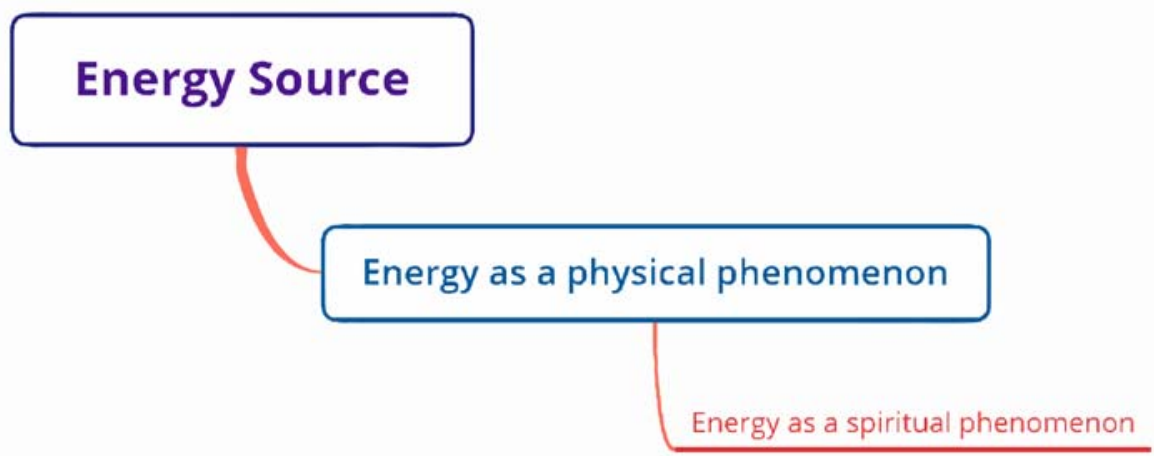

Fig. 8. Energy source as a synergy of philosophic, theological and physical images of reality.

\section{Discussion}

Thus, the certainty of events is a measure of the sustainability of society, as well as a tool through which humanity can regulate the future. In this case, the experience of cybernetics, engineering and technology is applied to solve scientific management problems. The predetermination of events, in turn, is that facet of being that demonstrates the manifestation of higher providence and higher meaning. In this case, a person goes beyond the limits of everyday life and reality, and this does not exclude a scientific approach, but, on the contrary, expands the horizons of consciousness and intellect. Management, in turn, acquires the features of universality. L. Drotianko, M. Abysova, N. Chenbai and T. Shorina have shown that post-non-classical science in all the diversity of its branches, spheres, is based on the synergetic principles of research unified for this stage of scientific knowledge, because science now does not deal with closed, but rather with complex, open, nonequilibrium systems characterized by the phenomena which are characterized by the phenomena of instability, coherence, fluctuations, etc., the description and research of which are most adequately provided today by synergetic as an interdisciplinary science with its most common cognitive means based on quantitative methods. Another thing is that these methods are universal at a certain historical stage in the science development and the next stage is likely to develop new approaches and methods of knowledge. This is all the more important in view of strengthening the practical orientation of modern post-nonclassical science. The very system of instrumental knowledge is becoming more open to new methodological tools, to the penetration into it of cognitive tools of other forms of knowledge (pre-scientific, para-scientific, religious, etc.) [11].

Non-random events in their transcendental meaning are presented as derivatives of philosophical and theological universals (highest power, highest meaning, highest design, creation of being), which gives rise to a synergy of various approaches, methods, principles that exclude at the same time an experimental study of these universals. To identify signs of the predestination of events, it takes a long time (for example, the personal life experience of an individual or the experience of entire generations) and colossal efforts for logical and scientific generalizations. Therefore, it is the philosophical studies of the non-random 
phenomenon that are most acceptable, since philosophy is in a constructive dialogue with science, theology, art, it balances on the verge of logic and absurdity, which does not contradict scientific research, but rather enriches it.

L. Drotianko, O. Shostak, M. Abysova, and N. Chenbai rightly argue that the goal of philosophical research in this context is a broad generalization of both the latest scientific theories and technologies to predict their future use, and the existing sociocultural implications of the high technologies with an assessment of their positive and negative effects on humans, nature, society and the planet as a whole. It is important to analyze these influences from the standpoint of socio-philosophical, philosophicalanthropological, cultural and philosophical knowledge as well as other humanity disciplines in their dialectical unity for the joint identification of the basic laws of the information society and to warn society about the undesirable for social dynamics outcomes [12].

Mathematical spheres of knowledge, in turn, specify the mechanisms for managing events in local systems, model tactics and strategies of everyday life, and create trajectories of the near future. To ensure the effective life of millions of people, information systems are created, decision support systems that regulate material and intellectual production on a global scale or within a global industry, development strategies for small and large companies are developed.

In particular, M. Simonova, Y. Lyachenkov and A. Kravchenko propose to formulate the strategic development model of the company using information systems that integrate corporate knowledge bases and the intelligent decision support system, which can eventually be transformed into the individual human development. However, the development of such a model requires a theoretical and methodological justification to use corporate knowledge bases, develop end-to-end information support and a structure based on the principles of system modeling. The proposed model can develop a software package project for managing labor potential in organizations, large enterprises, educational centers, universities, one of the significant elements of which should be a personnel selection system. The software package is necessary for planning career paths for employees using corporate knowledge bases in accordance with the organization's development strategy [13]. This approach shows that not a single mathematical model is able to take into account the individual characteristics of a person; rather, it presupposes general requirements and rules of behavior in the workplace, in business, in the management of companies, enterprises, corporations. In addition, the models used, for example, in the economy or in finance, can take into account various factors. That is, there are no universal general models for each specific information situation. So, the same economic model for different countries is not proportionally effective. Therefore, today, such models are proposed in terms of management qualities, that take into account qualitative growth that affects the development of various managed systems.

\section{Conclusion}

All of the above can be summarized as follows: firstly, the difference between random and non-random events is rather arbitrary. In philosophy, these categories can be represented as ambivalent but interdependent antinomies. Secondly, the process of converting randomness into non-randomness is quite laborious and it requires a long time and scientific approach (but in each field of knowledge it is different). As a result of this transformation, a pattern is revealed that allows synchronizing the synergy of scientific ideas, theories of being, scientific pictures of the world, as well as approaches to building a new everyday life in social virtuum. Thirdly, the definition of non-randomness as predetermination allows going beyond physical reality and allows us to consider it as a transcendental phenomenon. Thus, 
non-randomness is the effect of the manifestation of a highest cause as the main source of "constructive energy" (we proposed its conditional name). Random events are transformed into non-random events, since this is logical for the human mind and necessary for a comfortable life in society. The carrier of such energy is a person who survives more effectively in a sustainable model of society. If the social system becomes emergent, then applicable to historical time and the situation, appropriate approaches, evaluation criteria, methods, strategies and tactics are developed to minimize fluctuations.

\section{References}

1. I. Devterov, I. Skyba, E3S Web of Conferences 157, 04010 (2020) https://www.e3sconferences.org/articles/e3sconf/pdf/2020/17/e3sconf_ktti2020_04010.pdf

2. J. Kharchenko, S. Kharchenko, O. Sidorkina, A. Fabrika, O. Rusul, E3S Web of Conferences 157, $04012 \quad$ (2020) https://www.e3sconferences.org/articles/e3sconf/pdf/2020/17/e3sconf_ktti2020_04012.pdf

3. V. Chulkov, E3S Web of Conferences 157, 02025 (2020) https://www.e3sconferences.org/articles/e3sconf/pdf/2020/17/e3sconf_ktti2020_02025.pdf

4. N. Kazarinov, A. Smirnov, Y. Petrov, A. Gruzdkov, E3S Web of Conferences 157, $01020 \quad$ (2020)

https://www.e3sconferences.org/articles/e3sconf/pdf/2020/17/e3sconf_ktti2020_01020.pdf

5. A. Lyapunov, The general problem of the stability of motion (State publishing house of technical and theoretical literature, Moscow-Leningrad, 1950)
6. Lyapunov
Function
Method
Differential
http://www.math24.ru/\%D0\%BC\%D0\%B5\%D1\%82\%D0\%BE\%D0\%B4-
Equations,
$\% \mathrm{D} 1 \% 84 \% \mathrm{D} 1 \% 83 \% \mathrm{D} 0 \% \mathrm{BD} \% \mathrm{D} 0 \% \mathrm{BA} \% \mathrm{D} 1 \% 86 \% \mathrm{D} 0 \% \mathrm{~B} 8 \% \mathrm{D} 0 \% \mathrm{~B} 9-$
$\% \mathrm{D} 0 \% \mathrm{BB} \% \mathrm{D} 1 \% 8 \mathrm{~F} \% \mathrm{D} 0 \% \mathrm{BF} \% \mathrm{D} 1 \% 83 \% \mathrm{D} 0 \% \mathrm{BD} \% \mathrm{D} 0 \% \mathrm{BE} \% \mathrm{D} 0 \% \mathrm{~B} 2 \% \mathrm{D} 0 \% \mathrm{~B} 0 . \mathrm{html}$

7. L. Honyukova, H. Kleshnya, S. Ordenov, I. Skyba, E3S Web of Conferences 157, 04004

(2020)

https://www.e3sconferences.org/articles/e3sconf/pdf/2020/17/e3sconf_ktti2020_04004.pdf

8. O. Pirogova, V. Plotnikov, E3S Web of Conferences 157, 04007 (2020) https://www.e3s-conferences.org/articles/e3sconf/pdf/2020/17/e3sconf_ktti2020_ 04007.pdf

9. V. Kasyanov, E. Kosenko, V. Kosenko, V. Krymsky, E3S Web of Conferences 157, $02019 \quad(2020)$ https://www.e3sconferences.org/articles/e3sconf/pdf/2020/17/e3sconf_ktti2020_02019.pdf

10. I. Rosenberg, Modern management technologies 7(79), 7902 (2017) https://sovman.ru/article/7902/

11. L. Drotianko, M. Abysova, N. Chenbai, T. Shorina, E3S Web of Conferences 157, $04003 \quad$ (2020) https://www.e3sconferences.org/articles/e3sconf/pdf/2020/17/e3sconf_ktti2020_04003.pdf

12. L. Drotianko, O. Shostak, M. Abysova, N. Chenbai, E3S Web of Conferences 157, $04005 \quad$ (2020) https://www.e3sconferences.org/articles/e3sconf/pdf/2020/17/e3sconf_ktti2020_04005.pdf

13. M. Simonova, Y. Lyachenkov, A. Kravchenko, E3S Web of Conferences 157, 04024 (2020) https://www.e3s-conferences.org/articles/e3sconf/pdf/2020/17/e3sconf _ktti2020_04024.pdf 